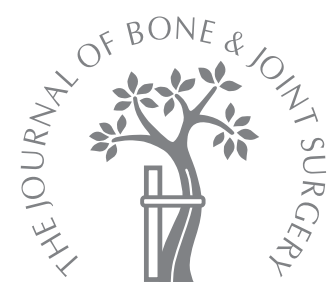

口 HIP

\title{
Femoral revision surgery with impaction bone grafting
}

\author{
31 HIPS FOLLOWED PROSPECTIVELY FOR TEN TO 15 YEARS
}

B. L. E. F. ten Have, R. W. Brouwer, F. C. van Biezen, J. A. N. Verhaar

From Orthopaedic

Department, University Hospital

Rotterdam,

Rotterdam, The

Netherlands

\footnotetext{
B. L. E. F. ten Have, MD, Consultant Orthopaedic Surgeon

R. W. Brouwer MD, PhD, Consultant Orthopaedic Surgeon

Martini Hospital Groningen, Orthopaedic Department, Van Swietenplein 1, Groningen 9728, The Netherlands.

F. C. van Biezen, MD, Consultant Orthopaedic Surgeon

J. A. N. Verhaar, MD, PhD Professor of Orthopaedic Surgery

University Hospital Rotterdam Orthopaedic Department 's-Gravendijkwal 230, 3015 CE Rotterdam, The Netherlands.

Correspondence should be sent to Dr B. L. E. F. ten Have; e-mail: havetenb@mzh.n
}

C2012 British Editorial Society of Bone and Joint Surgery doi:10.1302/0301-620X.94B5. $27909 \$ 2.00$

$J$ Bone Joint Surg $B$ 2012;94-B:615-18.

Received 4 July 2011: Accepted

after revision 5 January 2012

The purpose of this prospective study was to evaluate the long-term clinical and radiological outcomes of revision of the femoral component of a total hip replacement using impaction bone grafting. Femoral revision with an impacted allograft was performed on 29 patients (31 hips). In all, 21 hips (68\%) had grade III or IV femoral defects according to the Endo-Klinik classification. A total of 11 patients (12 hips) died before the ten-year follow-up period. Of the remaining patients, 18 patients (19 hips) were followed for 10 to 15 years; three further patients died during this time. None of the 31 stems underwent further revision of their stem. However, four stems showed extensive subsidence (>15 $\mathrm{mm}$ ). One of these patients had a femoral fracture that required fixation. Three other patients had a femoral fracture, two of which required fixation and the other was treated conservatively. Patients with a femoral fracture and/or severe subsidence had significantly more grade IV defects (six of seven hips; $p=0.004)$. One patient needed a closed reduction for dislocation.

Impaction allografting in revision hip surgery gives good long-term results for femora with grades I, II and III Endo-Klinik-classified defects. Extensive subsidence and femoral fractures were seen mainly in patients with grade IV damaged femora.

Impaction allografting has been widely used in revision total hip surgery since it was first described for the acetabulum ${ }^{1}$ and subsequently for the femur. ${ }^{2}$ An initial stable fixation of the stem in an impacted morcellised bone graft persists because of remodelling of the graft into host bone. Limitations to its use in the femur include the extent of femoral bone loss and the amount of graft that is needed. Hence several short- and mid-term studies show a significant incidence of stem subsidence and peri-prosthetic fracture. ${ }^{3-6}$ The only two long-term studies were published by the introducers of the technique. ${ }^{7,8}$ We present the results of a prospective study of 31 consecutive femoral revisions with 10.0 to 14.7 years' follow-up.

\section{Patients and Methods}

This prospective study was conducted in the orthopaedic department of a university hospital. Patients were included in the study if their pre-operative radiographs showed femoral defects needing impacted allograft augmentation. Pre-operative data were collected by one investigator (FCB).

Between September 1992 and September 1995, 29 patients (23 women and six men; 31 hips) were operated on. The mean age of the patients was 65 years ( 35 to 82 ). The mean body mass index (BMI) was $24.9 \mathrm{~kg} / \mathrm{m}^{2}$ (20 to
34). The Harris hip score (HHS) ${ }^{9}$ was recorded pre-operatively, with a distinction being made between total HHS (maximum 100 points for pain and function) and sub pain HHS (maximum 44 points). Other aspects that were recorded one day pre-operatively included the Trendelenburg sign, the Endo-Klinik ${ }^{10}$ and American Academy of Orthopaedic Surgeons classifications ${ }^{11}$ of the femoral defect pre-operatively, and if a previous trochanter osteotomy had been performed or not.

For 16 hips this was the first revision, for 12 the second, for two the third, and for one patient it was the fourth stem revision. A total of 25 hips were revised for aseptic loosening, three for aseptic loosening and peri-prosthetic fracture, and in two hips a Girdlestone excision arthroplasty was converted, and one stable uncemented stem was revised because of mid-thigh pain. A Charnley stem (DePuy International, Leeds, United Kingdom) was removed from ten hips, a McKee Arden (London Splint Company Ltd, London, United Kingdom) from five, a Müller (Speetec Implantate GMBH, Langelsheim, Germany) from four, a McKee Farrar (London Splint Company Ltd) from three, a Minneapolis (DePuy Orthopaedics, Warsaw, Indiana) from three, and from one each a Weber (Allopro, Baar, Switzerland), Judet (Tornier, Montbonnot, 
France), La Grange la Tournelle (unknown manufacturer), Osteonics Omnifit (Stryker, Waardenburg, The Netherlands), Lord (Benoist Girard, Bagneux, France) and Stanmore (Biomet Nederland BV, Dordrecht, Netherlands) stem.

The Girdlestone excision arthroplasty had been established in one patient for three years and the other for ten years. The Endo-Klinik bone loss of the femur was grade I in one hip, grade II in ten, grade III in nine and grade IV in 11 hips. According to the AAOS classification, one hip had solely cavitary defects; all other hips had combined segmental and cavitary defects; one also had femoral stenosis and four also had a peri-prosthetic fracture.

Surgical procedure. All operations were undertaken by one surgeon (FCB) using a technique described by Gie et $\mathrm{l}^{16}$ modified to involve a lateral approach and an osteotomy of the greater trochanter. A cement plug was placed at least $2 \mathrm{~cm}$ distal to the tip of the new stem or the most distal cortical defect in the femur. The femoral canal was reconstructed by impacting allograft bone chips obtained from fresh-frozen femoral heads using the Exeter X-change system. ${ }^{16}$ They were prepared into particles approximately $2 \mathrm{~mm}$ to $5 \mathrm{~mm}$ in diameter using a Novio Magus bone mill (Spierings Medische Techniek, Nijmegen, The Netherlands). Reinforcement of the proximal femur with meshes (Stryker), cerclage wires and/or AO acetabular plates (Synthes BV, Zeist, The Netherlands) was often necessary to withstand the forces when the graft was introduced. Finally, a standard Exeter stem (Stryker) was cemented in the neomedullary canal using erythromycin- and colistinsoaked Simplex cement (Stryker). The greater trochanter was reattached with a double-crossover wire and a compression spring, as described by Wroblewski and Shelley. ${ }^{12}$ Five femora needed no reinforcement prior to the impaction procedure, three needed Partridge cerclage wires (Stryker), seven needed cerclage wire and wire mesh, and 16 needed cerclage wire combined with mesh and a reconstruction plate.

During the operation and the first two post-operative days patients received intravenous antibiotics (cefamandol nafate (EuroCept BV, Ankeveen, The Netherlands), $1 \mathrm{~g}$ three times daily), and were confined to bed for six weeks. Thereafter, non-weight-bearing mobilisation continued for six weeks, followed by a further six weeks of increasing weight-bearing.

Patients were assessed three, six and 12 months postoperatively, and annually thereafter. Before February 1996 outcome measures were made by one observer (FCB), thereafter by a different observer (BTH). All radiographs were assessed by one observer (BTH).

Primary outcome measures were survival of the revised femoral component, post-operative femoral fracture and the incidence of severe subsidence (>15 mm). The degree of subsidence was assessed using the methods of Loudon and Charnley $^{13}$ and Fowler et $\mathrm{al}^{14}$ who used the trochanteric wires and the space between the cement mantle and the proximolateral stem surface as reference points. The most distinct distal point of osteosynthetic material was used as reference point when the trochanteric osteotomy was not consolidated. Secondary outcome measures were total HHS, sub-pain HHS and Trendelenburg sign.

The fixation of the stem and incorporation of the graft were scored radiographically. Radiolucent lines (RLLs) between stem and cement, and between cement and femoral bone, in each of the seven zones of Gruen ${ }^{15}$ were recorded. The radiological incorporation of the graft was evaluated based on the guidelines of Gie et al, ${ }^{16}$ distinguishing between cortical healing and trabecular incorporation. Cortical healing was considered to be represented by thickening of the cortex post-operatively in areas where it was thin or scalloped pre-operatively. Incorporation of the graft was considered to be represented by the appearance of trabeculae in the graft without any distinctive orientation. The distinctive trabecular network going from the endosteal cortex into the cement in the lines of the predominant stresses is called trabecular remodelling. Gruen zone 4 was divided into $4 \mathrm{a}$ (the lateral part) and $4 \mathrm{~b}$ (the medial part). Heterotopic ossification was graded according to the classification of Brooker et al. ${ }^{17}$

Statistical analysis. Survival was presented using KaplanMeier analysis with $95 \%$ confidence intervals (CI). In order to determine differences in secondary outcome parameters in relation to the pre-operative femoral defects according to the EndoKlinik classification, we used chi-squared tests for subsidence and fracture, and Student's $t$-tests for HHS. The SPSS software (SPSS Inc., Chicago, Illinois) was used for the statistical analyses and a p-value $\leq 0.05$ was considered significant.

\section{Results}

A total of 12 patients (13 hips) died before a ten-year follow-up could be undertaken. None of these had undergone a further revision. All had an increased HHS, although two had significant subsidence $(30 \mathrm{~mm}$ and $15 \mathrm{~mm}$, respectively); a further two patients (two hips) died after followup of more than ten years. Neither of these had undergone a revision. The 15 surviving patients (16 hips) have a mean follow-up of 12.6 years (10.0 to 14.7): one of these was not able to come for review and was interviewed by telephone.

None of the stems has been further revised. Taking postoperative femoral fracture needing reoperation and subsidence $>15 \mathrm{~mm}$ as an endpoint, seven hips (22.6\%) failed; six of these had grade 4 Endo-Klinik bone defects (out of a total of ten with a grade 4 defect), which was significantly more $(\mathrm{p}=0.004)$ than the hips with less than grade 4 defects (one failure of 21 hips). The overall survival rate was $77.4 \%$ with a mean survival of 11.6 years $(95 \%$ CI 9.6 to 13.5$)$.

Four patients (four hips) sustained a femoral fracture post-operatively and three underwent further surgery. One was treated conservatively. All fractures eventually united. There was severe subsidence in association with four stems (mean $27 \mathrm{~mm}$ (15 to 32)). Six had no signs of subsidence, and 21 subsided a mean of $3 \mathrm{~mm}$ (1 to 6). All four stems 


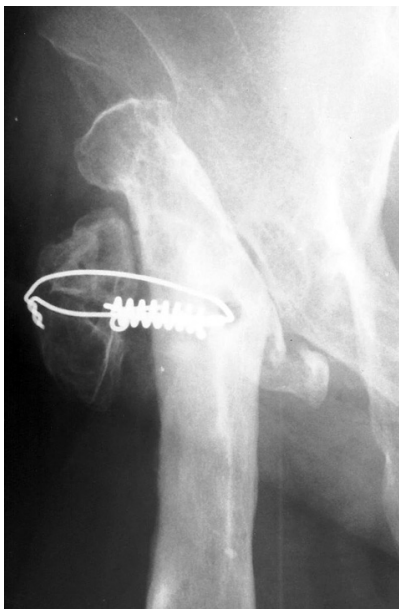

Fig. 1a

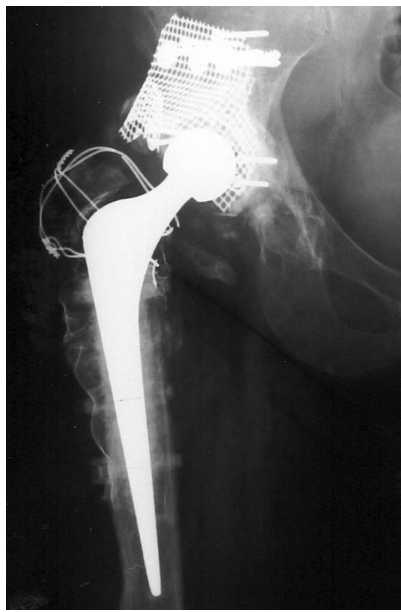

Fig. 1b
Radiographs of a 43-year-old female patient with rheumatoid arthritis who had undergone had a Girdlestone excision arthroplasty following a failed replacement (a). There were cortical defects in zones 1, 2 and 3, requiring a mesh and Partridge cerclage straps combined with an impacted allograft, with a satisfactory result at six years after revision (b), with a Harris hip score of 72 and no pain.

with severe subsidence had grade 4 Endo-Klinik femoral defects; two of these also had a pre-operative fracture of the shaft. All had at least one segmental defect and a complete cortical defect and hollowed proximal femur $>8 \mathrm{~cm}$ below the lesser trochanter. A stem that subsided $30 \mathrm{~mm}$ was the only one that migrated into a varus position. Three of these subsided $>10 \mathrm{~mm}$ within the first post-operative year.

Secondary outcome measures. Post-operatively, the mean HHS improved significantly from 43 (3 to 74 ) points preoperatively to 76 (22 to 98 ) at the latest follow-up (mean improvement of $33(95 \%$ CI 25.2 to 41.9$)$ ) ( $\mathrm{p}<0.001)$. The mean sub-pain HHS improved significantly from 18 (0 to 40) points pre-operatively to 39 (10 to 44 ) at the latest follow- up (mean improvement of 21 (95\% CI 16.6 to 26.3)) $(\mathrm{p}<0.001)$. Of the whole group, 26 patients showed a positive Trendelenburg sign pre-operatively, compared with eight at the final follow-up. There were no femoral radiolucencies at the cement-graft interface, but ten patients had a RLL at the stem-cement interface in zone 1, reflecting subsidence. All four severely subsided stems had continuing RLLs at the stem-cement interface from zone 1 into zone $4 \mathrm{a}$, or from zone 7 into zone 4b. Metallic reinforcement of the femur, especially in Gruen zone 7, disturbed the radiological evaluation in 54 of 248 zones $(22 \%)$. Resorption was seen in 11 of 194 zones $(6 \%)$, especially in zone 1 . Remodelling was seen in 170 of 194 zones $(88 \%)$, and in 70 zones $(36 \%)$ there was remodelling in association with cortical repair. In all ten hips showed no osseous consolidation of the greater trochanter.

Three years post-operatively one patient had a dislocation, which was managed by closed reduction. One patient had delayed wound healing, and nine months post-operatively had severe resorption of a massive acetabular allograft requiring revision with another allograft augmentation (Fig. 1). Another three patients developed aseptic loosening of the acetabular component at nine, ten and ten years, respectively.

\section{Discussion}

The introduction of impaction bone-grafting revolutionised revision surgery after total hip replacement. Good mid-term results have been reported ${ }^{2,4-6,18}$ and the initiators of the technique ${ }^{7,8}$ have also reported good long-term clinical results.

The process of remodelling impacted bone graft has been confirmed in animal and patient retrieval and biopsy studies. ${ }^{19,20}$ The issue of whether subsidence of the stem leading to axial loading of the bone graft is essential for remodelling of the graft into host bone remains controversial. We have previously compared the migration patterns of the Exeter stem (double-tapered subsiding) with those of the Elite stem (DePuy International) (collar-shaped non-subsiding). ${ }^{21}$ The Exeter stem showed significantly more subsidence in the first two years than the Elite stem, without differences in clinical outcome or radiological appearances of the graft.

Excessive subsidence and the risk of peri-prosthetic fractures seem to be the major drawbacks of impaction grafting. Besides the configuration of the stem, other causes for subsidence are identified. The initial stability of the graft is linearly correlated to the number of impaction blows performed onto the graft. ${ }^{22}$ The size of a bone graft also, of course, determines its biological and biomechanical characteristics. Large grafts may not remodel, resulting in collapse of the graft, and may thus allow subsidence. van der Donk et $\mathrm{al}^{23}$ and Linder ${ }^{24}$ obtained histological samples of patients two to ten years post-operatively that showed areas of necrosis within the bone graft. In our study, 11 hips with grade 4 Endo-Klinik defects needed substantial bone grafting; in four of these hips complete remodelling of the graft failed, resulting in excessive subsidence.

It is not yet entirely clear at what moment the processes of bone resorption and formation take place during remodelling, and what the effect of biomechanical stimulation is. In this respect the trend of increasing weight-bearing sooner after operation still has little scientific basis. Ornstein et al ${ }^{25}$ found similar migration patterns with radiostereogrammetric analysis (RSA) when comparing a group of post-operatively restricted weight-bearing patients with an unrestricted weight-bearing group.

A total of four patients $(13 \%)$ in our series suffered a femoral fracture post-operatively, all but one in the first six months, leading to a further revision rate of $10 \%$. All these patients had segmental defects at the level of the tip the prosthesis or below. A total of four stems (13\%), all with Endo-Klinik grade 4 defects, had severe subsidence. Further revision in three of these was not required; the other suffered a fracture after six years. The three stems that subsided by $>30 \mathrm{~mm}$ showed subsidence up to five years postoperatively. Ornstein et $\mathrm{al}^{26}$ found in an RSA study that 
11 of 15 Exeter stems migrated up to five years postoperatively, and as with our patients there was no further deterioration clinically or radiologically thereafter.

Our study shows excellent long-term clinical and radiological results in stem revision surgery for the Endo-Klinik grade 1, 2 and 3 damaged femora treated with impaction bone grafting. Those with severely damaged femora, with grade 4 Endo-Klinik changes, had an incidence of femoral fracture and/or subsidence of the stem of $>50 \%$. This was probably due to exceeding the biological and biomechanical potential of an impacted allograft to remodel into host bone.

By combining impaction allografting and a long stem in femoral revision surgery, femoral fracture and extensive subsidence may be prevented. Nonetheless, Sierra et $\mathrm{al}^{27}$ found that in a group of 34 patients with grades 3 and 4 EndoKlinik defects $64 \%$ failed for any reason, and six needed a further femoral procedure. Thus, in selected cases we now use long stems in combination with impaction allografting to prevent excessive subsidence and femoral fracture.

\section{Supplementary material}

藏 Diagrams detailing and enumerating the different findings in each Gruen zone, and two tables showing the baseline characteristics and outcomes of each patient are available with the electronic version of this article on our website www.jbjs.boneandjoint.org.uk

No benefits in any form have been received or will be received from a commercial party related directly or indirectly to the subject of this article.

\section{References}

1. Slooff TJ, Huiskes R, van Horn J, Lemmens AJ. Bone grafting in total hip replacement for acetabular protrusion. Acta Orthop Scand 1984;55:593-596.

2. Gie GA, Linder $\mathbf{L}$, Ling RS, et al. Impacted cancellous allografts and cement for revision total hip arthroplasty. J Bone Joint Surg [Br] 1993;75-B:14-21.

3. Eldridge JD, Smith EJ, Hubble MJ, Whitehouse SL, Learmonth ID. Massive early subsidence following femoral impaction grafting. J Arthroplasty 1997;12:535540.

4. Meding JB, Ritter MA, Keating EM, Faris PM. Impaction bone-grafting before insertion of a femoral stem with cement in revision total hip arthroplasty: a minimum two-year follow-up study. J Bone Joint Surg [Am] 1997;79-A:1834-1841.

5. Cabanela ME, Trousdale RT, Berry DJ. Impacted cancellous graft plus cement in hip revision. Clin Orthop Relat Res 2003;417:175-182.

6. Ullmark G, Hallin G, Nilsson 0. Impacted corticocancellous allografts and cement for revision of the femur component in total hip arthroplasty. J Arthroplasty 2002;17:140-149

7. Schreurs BW, Arts JJ, Verdonschot $\mathbf{N}$, et al. Femoral component revision with use of impaction bone-grafting and a cemented polished stem. J Bone Joint Surg [Am] 2005;87-A:2499-2507.
8. Halliday BR, English HW, Timperley AJ, Gie GA, Ling RS. Femoral impaction grafting with cement in revision total hip replacement: evolution of the technique and results. J Bone Joint Surg [Br] 2003;85-B:809-817.

9. Harris WH. Traumatic arthritis of the hip after dislocation and acetabular fractures: treatment by mold arthroplasty: an end-result study using a new method of result evaluation. J Bone Joint Surg [Am] 1969;51-A:737-755.

10. Engelbrecht $\mathbf{E}$, Heinert K. Klassifikation und behandlungsrichtlienen von knochensubstanzverlusten bei revisionsoperationen am huftgelenk: mittelfristige Ergebnisse. In: Primär- und revisions-alloarthroplastik Hüft- und Kniegelenk: 10 jahre endo-klinik Hamburg. Berlin: Springer-Verlag, 1987:189-201 (in German).

11. D'Antonio J, McCarthy JC, Bargar WL, et al. Classification of femoral abnormalities in total hip arthroplasty. Clin Orthop Relat Res 1993;296:133-139.

12. Wroblewski BM, Shelley P. Reattachment of the greater trochanter after hip replacement. J Bone Joint Surg [Br] 1985;67-B:736-740.

13. Loudon JR, Charnley J. Subsidence of the femoral prosthesis in total hip replacement in relation to the design of the stem. J Bone Joint Surg [Br] 1980;62-B:450-453.

14. Fowler JL, Gie GA, Lee AJ, Ling RS. Experience with the Exeter total hip replacement since 1970. Orthop Clin North Am 1988;19:477-489.

15. Gruen TA, McNeice GM, Amstutz HC. "Modes of failure" of cemented stem-type femoral components: a radiographic analysis of loosening. Clin Orthop Relat Res 1979;141:17-27.

16. Gie GA, Linder $\mathbf{L}$, Ling RS, et al. Contained morselized allograft in revision total hip arthroplasty: surgical technique. Orthop Clin North Am 1993;24:717-725.

17. Brooker AF, Bowerman JW, Robinson RA, Riley LH Jr. Ectopic ossification following total hip replacement: incidence and a method of classification. J Bone Joint Surg [Am] 1973;55-A:1629-1632

18. van Biezen FC, ten Have BL, Verhaar JA. Impaction bone-grafting of severely defective femora in revision total hip surgery: 21 hips followed for 41-85 months. Acta Orthop Scand 2000;71:135-142.

19. Schreurs BW, Buma P, Huiskes R, Slagter JL, Slooff TJ. Morsellized allografts for fixation of the hip prosthesis femoral component: a mechanical and histological study in the goat. Acta Orthop Scand 1994;65:267-275.

20. Buma P, Lamerigts N, Schreurs BW, Gardeniers J, Versleyen D, Slooff TJ. Impacted graft incorporation after cemented acetabular revision: histological evaluation in 8 patients. Acta Orthop Scand 1996;67:536-540.

21. van Doorn WJ, ten Have BL, van Biezen FC, et al. Migration of the femoral stem after impaction bone grafting: first results of an ongoing, randomised study of the exeter and elite plus femoral stems using radiostereometric analysis. J Bone Joint Surg [Br] 2002;84-B:825-831.

22. Kuiper JH, Netzet B, Pollitine P, et al. Bone density and particle size distribution influence early mechanical stability and cement penetration in impaction grafting [abstract]. Procs Eighth Annual Meeting of the European Orthopaedic Research Society, Amsterdam, The Netherlands, 1998.

23. van der Donk S, Buma P, Slooff TJ, Gardeniers JW, Schreurs BW. Incorporation of morselized bone grafts: a study of 24 acetabular biopsy specimens. Clin Orthop Relat Res 2002;396:131-141.

24. Linder L. Cancellous impaction grafting in the human femur: histological and radiographic observations in 6 autopsy femurs and 8 biopsies. Acta Orthop Scand 2000;71:543-552

25. Ornstein E, Franzén H, Johnsson R, et al. Hip revision with impacted morselized allografts: unrestricted weight-bearing and restricted weight-bearing have simila effect on migration: a radiostereometry analysis. Arch Orthop Trauma Surg 2003;123:261-267

26. Ornstein $\mathbf{E}$, Franzén $\mathbf{H}$, Johnsson $\mathbf{R}$, et al. Hip revision using the Exeter stem impacted morselized allograft bone and cement: a consecutive 5-year radiostereometric and radiographic study in 15 hips. Acta Orthop Scand 2004;75:533-543.

27. Sierra RJ, Charity J, Tsiridis E, Timperley JA, Gie GA. The use of long cemented stems for femoral impaction grafting in revision total hip arthroplasty. J Bone Joint Surg [Am] 2008;90-A:1330-1336. 